\title{
CLOUD COMPUTING ACTIVITIES: GUIDELINES ON THE SOUTH AFRICAN INCOME TAX CLASSIFICATION
}

\author{
Shené Steenkamp* \\ Stellenbosch University \\ shenev@sun.ac.za
}

Received: March 2015

\author{
Rudie Nel" \\ Stellenbosch University \\ rnel@sun.ac.za
}

Accepted: September 2015

\begin{abstract}
The classification of income from cloud computing activities, according to the substance-over-form doctrine, is fundamental to the application of the correct taxation source test. The designation of laaS, PaaS and SaaS, the three main cloud computing service models, clearly denotes the form of cloud computing activities as that of a service. However, the nature of cloud computing inherently raises the question of whether or not cloud computing income should not rather be classified as income from leasing activities or the imparting of know-how. In fact, the findings of this study suggest the classification would not necessarily always be that of a service. The possible classification as lease income can be either income from the lease of tangible computer hardware and/or of intellectual property (royalty income). The aim of this study was to formulate guidelines to assist in the correct classification of income from cloud computing activities. This was achieved by performing doctrinal research based on the South African and international literature.
\end{abstract}

Keywords

Income tax classification, section 9 of Income Tax Act, Cloud computing, Know-how, Lease, Intellectual property, Royalties

*Ms S Steenkamp is a lecturer in the School of Accountancy, Stellenbosch University, South Africa.

\#Mr R Nel is a senior lecturer in the School of Accountancy, Stellenbosch University, South Africa. 


\section{INTRODUCTION}

The assessment of normal income tax in South Africa relies in part on the source rules in determining whether the underlying income is from a source in South Africa and consequently subjected to income tax. The South African source rules are dependent on the correct classification of a transaction based on the true nature of transactions in accordance with the 'substance over form' doctrine (Zandberg v Van Zyl 1910 AD 302). The internet as a platform to conduct business has changed and may even disguise the true nature of business activities (Oguttu \& Van der Merwe, 2005) and cloud computing, a refined form of such internet activities, is therefore no exception to the risk of its form not being representative of its true nature.

Cloud computing is defined by the National Institute of Standards and Technology (NIST) (Mell \& Grance, 2011) as 'a model for enabling ubiquitous, convenient, on-demand network access to a shared pool of configurable computing resources (e.g. networks, servers, storage, applications, and servers) that can be rapidly provisioned and released with minimal management effort or service provider interaction'. This widely used cloud model by NIST (Mell \& Grance, 2011) comprises three main service models, namely Cloud infrastructure as a Service (laaS), Cloud platform as a Service (PaaS) and Cloud software as a Service (SaaS). The taxonomy of the cloud service model as laaS, PaaS or SaaS is determined by the specific computing resources to which the consumer is granted access via the internet. From the NIST (Mell \& Grance, 2011) cloud computing model the computing resources underlying the service models broadly comprise computer hardware (IaaS) and computer programs (PaaS and SaaS). From the denomination of the cloud service models, seemingly, the income tax classification of cloud computing according to its form is that of a service. However, cloud computing represents a refined extension of information technology outsourcing wherein consumers benefit not merely from the use of enhanced computing resources, but may also distance themselves from ownership of computing resources (Smith \& Clearley, 2012).

This necessitates an investigation of whether the apparent service classification in fact represents or disguises the true nature of cloud activities, particularly since the use of computing resources within the cloud computing realm bears relation to the general definition of a lease. A lease is an agreement whereby the lessor conveys to the lessee, in return for a payment or series of payments, the right to use an asset (resource) for an agreed period of time (IASB, 2010). This lease definition is also consistent with the definition of royalty income as provided in section 9(1) of the Income Tax Act 58 of 1962 (the Act) which reads as follows: 'received or accrued in respect of the use, right of use or permission to use any intellectual property as defined in section 23I'. For income tax purposes lease income can, therefore, be classified into lease income from tangible resources or intangible intellectual property (IP), the latter being categorised as royalty income in section 9 of the Act. Evidently, considering whether the true nature of cloud computing activities may, in fact, be that of leasing activities should be investigated by establishing whether such activities convey to the consumer any right of use in the underlying computing resources, be it tangible or intangible. The description of the computing resources will then determine the classification as either lease income from tangible resources, such as computer hardware, or royalty income from the lease of intangible IP (as defined in section 23I of the Act).

Section 231 of the Act refers to any registered IP, property or right, as per the various acts listed in section 23I, and knowledge connected to the use of such registered IP, property or right and will typically include a registered copyright of software of the cloud service provider (CSP). In the context of cloud-computing services closely related know-how may also represent a computing 
resource to which consumers may be granted access to. Know-how is generally regarded as unregistered special knowledge (OECD, 2012b) and, therefore, although it is similar in nature to $I P$, it falls outside the scope of section $23 I$ of the Act and is therefore categorised independently from royalty income in section 9 of the Act. Section 9(2)(e) and (f) of the Act refers to this income category as income received from the imparting of scientific, technical, industrial or commercial knowledge, which will be collectively referred to as know-how (SARS, 2012). The imparting of know-how is in nature dissimilar to the conveyance of a right to use a resource and is therefore independent from the lease income classification. However, over and above the lease income classification, the imparting of know-how does denote another possible income classification for cloud computing activities to consider.

It is evident that the classification of cloud computing income according to its form as that of a service becomes questionable. For income tax purposes the classification of the income earned by CSPs from the provision of these computing resources, under the faculty of one or a combination of the service models, will subsequently determine its relevant source rules. Firstly, source rules are determined based on the income categories disclosed in section 9 of the Act. Residually, by omission of an income category in section 9 of the Act, the applicable source rules are determined in accordance with common law doctrines (SARS, 2012:95). The importance of the income tax classification lies in the fact that it could result in an inclusion in the gross income of a taxpayer in South Africa and could therefore also affect the South African tax base. A deficiency in the correct classification of cloud computing income will result in inaccurate source tests, which may lead to tax leakages and loss of income to the fiscus.

Consequently, from an income tax perspective, there is a need for guidelines that may indicate the true income classification of cloud computing activities as being either service income, income from the lease of tangibles, royalty income or income from the imparting of know-how. This requires an investigation into whether cloud computing results in the consumer obtaining a vested right to use the CSP's computing resources and/or whether know-how is imparted to the consumer when access is granted to resources. It is submitted that, in the event of no rights being conveyed by the CSP or in the event of know-how not being imparted to the consumer, that the income tax classification is that of service income. This is illustrated in FIGURE 1 , which is also indicative of the structure of the consecutive sections ( $\S$ ) to follow in the study.

\section{RESEARCH OBJECTIVE AND RESEARCH METHOD}

The objective of this study is to identify guidelines to facilitate the correct income tax classification of cloud computing activities based on the underlying computing resources to such activities as indicated in FIGURE 1 . The aim of this study is not to provide comprehensive guidelines for the income tax classification of the exhaustive list of cloud computing possibilities and resources, but rather to provide general guidelines for the classification of the provision of the three main cloud computing resources as illustrated in FIGURE 1.

This objective was achieved by the identification of the applicable legal requirements contained in the Act. The legal requirements were then analysed based on case law and other available literature to identify challenges noted in the income classification of cloud computing services. The research strategy followed is therefore regarded as doctrinal in nature and is described by Hutchinson and Duncan (2012:101) as 'research which provides a systematic exposition of the rules governing a particular legal category, analyses the relationships between rules, explains areas of difficulty and, perhaps, predicts future developments'. 


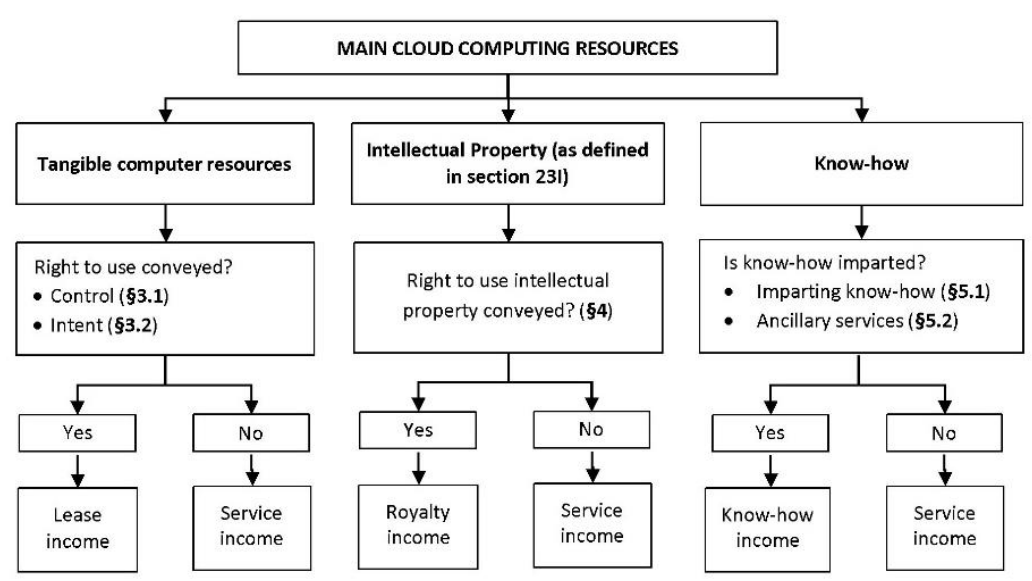

\section{FIGURE 1: Main cloud computing resources and its possible income tax classifications}

\section{Source: Authors'analysis and summary}

Literature includes international studies on the classification of internet transactions, applicable reports by Organisation for Economic Co-operation and Development (OECD), the relevant provisions of the Act, the Copyright Act no. 98 of 1978 (the Copyright Act), published articles, reports from SARS and textbooks relating to the objective. Furthermore, sections $9(2)(e)$ and $(f)$ of the Act were analysed to enable the identification of guidelines that may indicate whether or not cloud computing results in the imparting of know-how.

The identification of guidelines on the income classification of cloud computing could assist the South African tax authorities in preventing possible tax leakage in the cloud computing internet realm due to the prevailing uncertainty relating to the income classification of cloud computing. It may further assist the South African tax authorities in identifying unprecedented tax challenges regarding the global cloud computing phenomenon and could assist in attempts to align taxation laws to embrace the change in cross-border economic activities within the internet realm. Furthermore, it could be functional to CSPs' tax planning procedures when cloud contracts are concluded with South African residents.

Attainment of the objective of this study necessitates an investigation of:

- whether or not CSPs convey the right to use tangible computer hardware to consumers;

- whether or not CSPs convey the right to use IP as defined in section 231 of the Act to consumers; and

- whether or not CSPs impart know-how to consumers in conformity with section $9(2)(e)$ and (f) of the Act.

Based on the above investigation, guidelines on the income tax classification were formulated. Furthermore, any challenges identified in the formulation and possible application of these guidelines were included in a concluding summary. 


\section{THE RIGHT TO USE TANGIBLE COMPUTER HARDWARE}

As a principle of law, a right to use tangible property vests only in the party that holds the bare detention, and not the ownership, of the underlying property, and the two prerequisites for bare detention are control of the underlying resource and the wilful intention to do so (Van der Walt \& Pienaar, 1999). Control does not imply a narrow interpretation of physical possession, but should rather be interpreted from a functional viewpoint; and intention is established on the basis of the appearance or actions of the parties to an agreement, rather than the subjective intentions of parties (Van der Walt \& Pienaar, 1999). Accordingly, income earned from cloud computing will be classified as lease income only if the relevant facts of the case result in the consumer having functional control of the computer hardware and if this control by the consumer was also intended by the contracting parties. Under these two successive prerequisites of bare detention (control and intention), guidelines have been identified to facilitate an inquest into which party to a cloud computing agreement holds the bare detention of computer hardware. The identified guidelines are explicated under the faculty of each of these contributory elements to bare detention, namely control and intent in $\S 3.1$ and $\S 3.2$ respectively.

\subsection{Control}

The nature of the underlying resource and its use (purpose) are the two elements that should be taken into account when considering with whom control of the resource resides (Van der Walt \& Pienaar, 1999). These two elements may be closely related and are often interdependent, as is the case in the context of cloud computing regarding the making available of computer hardware. Put simply, the use (and purpose) of computer hardware is a means of input and output, to carry out instructions of the operational and/or application software and to provide memory for storage. The use of computer hardware is, however, dependent on its speed and capacity (its nature), which will determine which software it can run and the size of its storage capacity. The nature and use of computer hardware, the underlying resource to laas, marks the following extract from the definition of laaS as significant:

The consumer does not manage or control the underlying cloud infrastructure but has control over operating systems, storage, and deployed applications; and possibly limited control of selected networking components (e.g. host firewalls) (Mell \& Grance, 2011).

From this extract it is evident that the control of computer hardware exists simultaneously between the CSP and the consumer, as the former controls the speed and capacity of the hardware provided and the latter has control over the choice of software, operating systems and/or files that are deployed on the hardware. Although the control exercised by the consumer is limited to and dependent on the speed and capacity provided by the CSP, the consumer does have an element of control over the hardware.

If concurrent control exists, the party who is in the strongest and closest relation to a resource is regarded as ultimately exercising control and should be identified based on the relevant facts of each case (Van der Walt \& Pienaar, 1999). However, a non-exhaustive list of specific guidelines has been compiled to facilitate the process of identifying with whom significant control of a resource resides. This list was largely compiled from the USA Internal Revenue Code section 7701 (e), which comprises a non-exhaustive list of factors to consider in distinguishing between lease and service income (USA. Internal Revenue Code (26 U.S.C.)). All international literature was applied within and amended according to the South African context of this study. The list compiled 
in this study comprises merely guidelines that may be of assistance in the pursuit to identify with whom significant control resides, which should ultimately be based on the facts related to the specific case. In addition, such a pursuit means that, for each party involved, the contribution of each guideline that points towards control will have to be reflected upon. If each guideline carries an equal amount of weight, the party to whom control is pointed out by the foremost number of guidelines should be regarded as having significant control.

The following guidelines have been identified and expanded from the USA Internal Revenue Code section 7701(e) (USA Internal Revenue Service Revenue Rule 2011-24) and are subsequently considered:

- Physical possession of; or access to the resource

- Decision power relating to the destination of the resource

- Operation of the resource

- Deployment model

- The bearer of risks in the case of non-performance

\subsubsection{Physical possession of or access to the resource}

Physical possession of resources is included in the USA Internal Revenue Code section 7701(e) as one of the factors to consider in determining the classification of a transaction (USA Internal Revenue Code (26 U.S.C.)). It is submitted that physical possession of, or access to, a resource is not a prerequisite of control, but rather a factor to consider in determining with whom functional/significant control resides. However, physical possession is seemingly considered a deciding factor by the $0 E C D(2012 b)$ in assessing the true nature of leasing agreements for satellite transponders, cables for transmissions of electrical power or communications and telecommunication roaming agreements. The $0 \varepsilon C D$ (2012b) contended that the use of the mentioned equipment is to be classified as a service rather than as a lease. This conclusion was based on the fact that the user does not acquire physical possession of, or physical access to, the equipment that has been assigned to him (OECD, 2012b). In the absence of physical possession the result is that the lessee simply utilises the underlying asset's capacity, rather than controlling it $(0 \varepsilon C D, 2012 b)$. This statement may also be valid within the context of cloud computing where physical possession and access to computer hardware by consumers may be absent depending on the location of the hardware.

\subsubsection{Decision power relating to the destination of the resource}

The attribute of computer hardware as being moveable may imply that deciding its movement (i.e. the destination of the computer hardware) may indicate a form of control. It is essential to point out that physical possession of resources does not inherently imply that the decision power relating to the physical destination of resources also exists. Scenarios may exist where physical possession of computer hardware indicates that control resides with the CSP; nonetheless consumers have control over its ultimate destination, since certain cloud computing agreements may allow consumers to determine the location in which they want their computing to be provisioned (Leong, 2011; Hestermann, 2012). However, this control by the consumer is dependent on and limited to either the number of locations in which the CSP's computer hardware is situated at the time when the consumer's choice is made, and/or to which the CSP is willing to move its computer hardware. This possible form of control over computer hardware by the consumer is therefore similar to the control residing with consumers by means of their choosing the software, 
operating systems and/or files that are deployed on the computer hardware, the main similarity being that such control by the consumer is dependent on the control first exercised by the CSP. The significance of this control gained by the consumer, in comparison to that of the CSP, should therefore be considered.

\subsubsection{Operation of the resource}

Continued, uninterrupted use of a resource, without requiring interference from third parties, should be considered when identifying the party with significant control (Van der Walt \& Pienaar, 1999). If the full utilisation of the benefits of cloud computing by the consumer is dependent on a third-party performing an action, procedure or function, it may indicate that control does not reside with the consumer.

Actions, procedures or functions may include updating, removal and/or maintenance of the resources (0ECD, 2003; 2012c). It should be borne in mind that one of the significant benefits of cloud computing is the use of up-to-date technology infrastructures (Enslin, 2012). This benefit fundamentally implies that some action relating to the updating of computer resources may be required to be performed by the CSP. In addition, bundled maintenance, which places the responsibility of maintaining computer resources on the CSP, is very common in cloud computing (Cummings, 2012). Although bundled maintenance is common, it is not necessarily inherent to cloud computing service level agreements (Enslin, 2012). Therefore, when considering bundled maintenance as a factor that may indicate control, the underlying service level agreement to each cloud computing transaction should be thoroughly investigated. Furthermore, the party responsible for the operation/management of the cloud infrastructure, be it in-house information technology divisions or third-party CSPs, requires consideration in establishing control over the cloud infrastructure. From an American tax perspective, the tax authorities concluded that the responsibility of the CSP to program and control the information technology systems (Hellerstein \& Sedon, 2012) and to provide cloud security measures (USA Wis. Private Letter Rul W1025002; W0921002) indicate that control resides with the CSP rather than with the consumer.

The consequences for both the consumer and the CSP in the case of non-performance will therefore have to be considered and may depend on whether cloud infrastructures are managed in-house by the consumer or by the third-party CSP. An example of non-performance would be the malfunctioning of the computer hardware that is utilised by the consumer. This may mean that the computing requirements of the consumer are not delivered by the CSP. Consequently, without interference from the CSP (i.e. repairs or substitution), the consumer cannot successfully use the computer hardware the way it was intended to be utilised. The required intermission of the CSP to enable the use of the resources will therefore result in control residing with the CSP.

\subsubsection{Deployment model}

The widely used cloud model by NIST (Mell \& Grance, 2011) comprises four main deployment models, namely a public, private, community and hybrid cloud, with the distinguishing feature between the four deployment models being to whom the cloud resources are being made available. To whom computer hardware is made available can indicate with whom control of computer hardware resides.

Based on the definition by NIST (Mell \& Grant, 2011), a public cloud results in unrelated consumers concurrently competing for the use of the CSP's computer hardware-related capabilities 
according to its available capacity. If resources are simultaneously used by (or made available to) consumers that are unrelated to one another, a transaction should be treated as that of a service, rather than that of a lease (OECD, 2003). This principle of concurrent use is consistent with South African principles of law wherein joint control of tangibles can exist only in situations where control is shared and not competed for (Van der Walt \& Pienaar, 1999). This implies that consumers of cloud computing, which is deployed on a public cloud, do not control the computer hardware and in such transactions the control therefore resides with the CSP.

In contrast to a public cloud, in a private cloud the underlying computer hardware resources are exclusively used by one consumer. This may indicate that some control resides with the consumer within a private cloud.

In a community cloud, it may be argued that joint control by the users of this cloud exists, as there may be no competing for cloud capacity. Rather than competing for hardware capacity, the aim of a community cloud is to share information or knowledge relating to a shared concern (Mell \& Grant, 2011). The significance of the control applied by the consumers under both the public and community clouds should be determined in relation to the control applied by CSPs. This comparison may be done with reference to the other guidelines that indicate control, which are specified in the study.

A hybrid cloud is a configuration of two or more individual cloud deployment models. These models are technologically connected for the purpose of portability of cloud contents, but remain exclusive infrastructures (Mell \& Grant, 2011). Deciding with whom control of a hybrid cloud resides will have to be based on the individual clouds configured in the hybrid. Each individual cloud will be evaluated on the basis of the abovementioned examination of the other three deployment models.

\subsubsection{The bearer of risks in case of non-performance}

In classifying transactions, the USA Internal Revenue Code section 7701(e) (USA. Internal Revenue Code (26 U.S.C.)) considers who the bearer of the 'substantial risk of non-performance' (i.e. hardware malfunction) is, specifically referring to a financial risk (USA Internal Revenue Service Revenue Rule 2011-24). If the provider does not bear the financial risk of considerably reduced receipts or increased expenditure for non-performance under a contract, the transaction should be treated as a lease. If a transaction is regarded as that of a lease, it inherently implies that the consumer is regarded as having significant control over the underlying resource. It follows that the bearer of financial risk regarding the use of resources may indirectly indicate who controls such resources. From a cloud computing perspective, the mechanism for reimbursing consumers in the event of non-compliance of performance targets that are specified in the service level agreements, if any, will have to be scrutinised to determine whether or not CSPs will bear financial losses due to such non-compliance.

The preceding discussions (under $\S 3.1$ ) pertained to considerations in respect of control. The next line of inquiry (based on FIGURE 1) to formulate guidelines on the income tax classification of tangible computer resources as either lease income or service income would be to consider the factor of intent.

\subsection{Intent}

Intent refers to the mentality or intention with which a resource is controlled, both of which are a question of fact rather than law (Van der Walt \& Pienaar, 1999). In determining the intent with 
which contracting parties enter into an agreement, the transaction will therefore have to be interpreted based on the relevant facts of the case. This may prove to be difficult, as the form of a contract may be different to its real intention (Zandberg $v$ Van Zyl 1910 AD 302). The tenor of cloud computing agreements is that of a service. However, when all relevant guidelines indicate that the consumer has significant control over computer hardware, as discussed in $\S 3.1$, the classification as a service will have to be reassessed. The possibility that the substance or the real intent of the cloud agreement is that of a lease will have to be considered for each cloud agreement individually. The main object of such assessment is to establish whether the parties wilfully (Van der Walt \& Pienaar, 1999) and honestly (Commissioner of Customs and Excise $v$ Randles Bros \& Hudson Ltd 1941 AD 369) intended such an agreement to be a lease rather than a service. It is not suggested that the parties to a cloud computing agreement are malicious or intentionally trying to conceal the true nature of cloud agreements. Rather, the communal use of cloud computing as a service may or may not represent the true substance of a cloud computing contract due the intricate nature and expectations of cloud computing as a technology. If, however, a service is what the CSP and consumer honestly intended the cloud transaction to be, the transaction will accordingly be interpreted based on its tenor (Commissioner of Customs and Excise $v$ Randles Bros \& Hudson Ltd 1941 AD 369).

It would appear that establishing the true intent with which parties enter into a cloud computing agreement may not be a simple task, as it may encompass numerous possibilities which will have to be established on the basis of the relevant facts of each contract. This may prove to be difficult and time consuming and may require some guidance from the taxation authorities to ease the income classification of the use of tangible computer hardware within the cloud computing realm.

\subsection{Summary: right to use intangible computer hardware}

Only income received for the making available of cloud-based computer hardware that results in the consumer having significant control over such hardware can be considered to fall under the lease income classification. Furthermore, such income will be classified as lease income only once it has been established that a lease was also the true intent of the parties involved.

The findings of this study suggest that simultaneous control over tangible computer resources by the consumer and the CSP exists. In such cases, the party with whom significant control resides is regarded as ultimately controlling the computer resource. The identification of the party with whom significant control resides may be assisted by the non-exhaustive list of guidelines discussed in $\S 3.1 .1$ to $§ 3.1 .5$, but should ultimately be decided on the merit of each cloud computing case. If these guidelines indicate that significant control resides with the CSP, then payments received for the use of computer hardware should be classified as service income. However, if these guidelines indicate that significant control resides with the consumer, the intent of the parties to the cloud contract will have to be investigated. It then has to be established whether the wilful and honest intent of parties to a cloud computing agreement is in accordance with its form, which is a service. Establishing such intent is based on the true object, the dominant purpose and the essence of the transaction under review (these terms are used interchangeably). The essence of the transaction refers to the services the consumer is essentially paying for and will have to be considered based on the relevant facts bearing to each cloud contract. Only once the consumer of cloud computing has significant control over tangible computer resources, and it is established that this was also the wilful intent of the parties to the agreement, will the cloud transaction be classified as lease income. 
With reference to FIGURE 1, as opposed to the use of computer hardware and the lease income classification of cloud transactions, cloud computing activities also entail the use of intangible IP, as defined in section 23I of the Act. Therefore, it needs to be considered whether income earned from the use of IP should be classified as royalty rather than service income.

\section{THE RIGHT TO USE INTELLECTUAL PROPERTY CONVEYED}

IP as defined in section 23I of the Act refers specifically to any registered IP, any property or right of a similar nature to registered IP and any knowledge connected to the use of such registered IP or any property or right of a similar nature. It appears that in its entirety section 23I, and therefore royalty income, refers to IP that is registered as per the relevant acts mentioned in section 231. Considering whether any rights in the intangible computer programs vest in the consumer under cloud computing requires consideration of the specific requirements of section $11 \mathrm{~B}$ and $19 \mathrm{~B}(2)$ of the Copyright Act.

In the context of cloud computing services the PaaS and SaaS service models might include computer programs, that are protected under the Copyright Act in South Africa, being made available to the consumer. The consumer will make use of the copyright in computer programs owned by the CSP only if the CSP does in fact convey any of the rights listed in section 11 B of the Copyright Act to the consumer, being the right to: reproduce, publish, perform in public, broadcast, adapt or let the said computer program. The right conveyed in terms of section $11 \mathrm{~B}$ is therefore considered to be the commercial exploitation of computer programs. Therefore, the mere use of computer programs, of which the copyright is retained by CSPs, for personal consumption or consumption in the day-to-day business activities by consumers would not result in the computer programs being commercially exploited. This also seems to be the approach followed in section $19 \mathrm{~B}(2)$ of the Copyright Act. Patently, this matter required no further investigation and it seems that only in cases where consumers apply the CSP's computer programs in a manner that would constitute the commercial exploitation of the resource will payments for cloud computing be considered to be royalty payments. If such payments received do not constitute royalty income, by the process of elimination such payments received will then be regarded as income from services rendered (a summary of the guidelines to classify cloud income as royalty income is provided in FIGURE 2 under $\S 6$ ). However, with reference to FIGURE 1 , the use of intangible computer resources which are retained by the CSP also necessitates a consideration of whether closely related know-how is imparted to the consumer through the cloud computing activities.

\section{THE IMPARTING OF KNOW-HOW: SECTION 9(2)(e) AND (f) OF THE ACT}

An analysis of the true nature of the use of intangible computer resources needs to be broadened to include the imparting of scientific, technical, industrial or commercial knowledge, assistance or services. This is commonly referred to as know-how (SARS, 2012), which is covered in section $9(2)(e)$ and ( $f$ ) of the Act separately from royalty income. However, the inclusion of know-how under this separate section of the Act is based on the same two-part source test that is applicable to royalty income. The use of an identical two-part source test for both royalty income and knowhow implies a shared connection between the income earned as royalty and from the imparting of know-how. This relation is consistent with international tax treaty principles disclosed by the $0 \varepsilon C D$ in the definition of royalty income, which includes information concerning industrial, 
commercial or scientific experience (OECD, 2012a). The words 'information concerning industrial, commercial or scientific experience' included in the definition of royalties by the OECD (2012a) refer to shared information that generally does not fall within the scope of IP, but that represents closely related know-how (OECD, 2012b). It appears that know-how entails unregistered knowledge/information that, although closely related to IP, falls outside the scope of registered IP as defined in section 23I of the Act.

The income category covered under sections $9(2)(e)$ and ( $f$ ) of the Act that relate to know-how can broadly be broken down and were subsequently explored as:

- Primary category: Income earned from imparting any knowledge or information of a scientific, technical, industrial or commercial nature; or

- Secondary category: Income earned from rendering any assistance or service in connection with the application or utilisation of such knowledge of information (ancillary services to know-how).

\subsection{Primary category: Imparting know-how}

To impart means to make known, and in the context of section 9(2)(e) and (f) of the Act that which should be made known, i.e. knowledge or information, is know-how that is closely related to royalties (SARS, 2012; 0ECD, 2012b). Know-how is characterised by the OECD (2012b) based on the following guidelines:

- Undisclosed knowledge or information; and

- that is obtained from past experience; and

- that can be practically applied within an operation or enterprise for its own account; and

- where the application of such knowledge or information will lead to an economic benefit to the receiver of it.

Undisclosed knowledge refers to knowledge that is not generally made known to the public, but that is supplied to the consumer under circumstances where specific provisions regarding the secrecy of such knowledge apply (0ECD, 2012b). This knowledge has to be gained from past experience, which, in itself, implies that it excludes consideration for new information compiled at the request of the consumer (OECD, 2012b). In a summarised version, these first two characteristics of know-how collectively refer to the nature of information that constitutes know-how. It is therefore fundamental, firstly, to draw attention to the nature of the information that is made available to consumers within cloud computing. If cloud computing does result in the CSP imparting knowledge to the consumer, such knowledge should be the secret knowledge underlying information technology resources, such as programming languages, to be classified as know-how. The imparting of know-how is therefore in contrast to the making available of the result of such knowledge, which is the cloud infrastructure itself. The making available of the actual know-how versus the making available of the result of know-how should therefore not be confused (Wesson, 1999).

Secondly, if the shared information complies with the nature of know-how, the manner in which it is applied within the consumer's organisation will then ultimately influence the characterisation of information as that of know-how. This refers collectively to the last two of the abovementioned characteristics. This secret or special knowledge has to be applied within an operation without the grantor playing any part in the application other than supplying such knowledge (OECD, 
2012b). Furthermore, it has to be applied and utilised by the receiver in a manner that constitutes commercial exploitation rather than the private use of such knowledge.

Consequently, if the consumers of cloud computing utilise the result of know-how for personal consumption, rather than the actual special knowledge itself for commercial exploitation such as reproduction, it will result in the supply of services. A summary on the guidelines related to the primary category of sections $9(2)(e)$ and $(f)$ is provided in FIGURE 2 under $\S 6$.

\subsection{Secondary category: Ancillary services to know-how}

It is imperative to emphasise that the secondary category refers to the rendering of assistance or services, which, in the context of section 9(2)(e) and (f) of the Act, are narrowed down to be in connection with the application or utilisation of know-how. In this limitation to the nature of services which fall within the scope of the secondary category, the wording 'in connection with', is inherently vague. Synonyms for this wording include 'relating to', 'regarding' or 'in respect of' (Concise Oxford Dictionary, 2012). However, the degree or strength that this service should be linked or related to know-how is unclear, since the words 'in connection with' inherently provide some level of flexibility in interpreting this secondary test, which may cause problems. SARS (2009) referred to the words 'connected to' as 'knowledge essential to the use of ...' and accordingly states that the words 'essential to' are more rigid than the words 'connected to'. The words 'essential to' automatically grant much less flexibility regarding the interpretation of this secondary test. It follows, then, that there is a need for a disclosure of the degree of the connection referred to in section $9(2)(e)$ and ( $f$ ) of the Act.

Nevertheless, whatever the uncertainty may be relating to the degree of such connection, there should be a connection to the application or utilisation of know-how. Therefore, the words 'in connection with' indicate that know-how should first have been imparted under the primary category before it can be considered whether cloud computing may be encompassed in the scope of the secondary test. A summary on the guidelines related to the secondary category of sections $9(2)(e)$ and $(f)$ is provided in FIGURE 2 under $\S 6$.

\section{SUMMARY: RIGHT TO USE IP AND THE IMPARTING OF KNOW-HOW AND ANCILLARY SERVICES}

A summary of the guidelines that may facilitate the income tax classification of cloud computing as either royalty income or its closely related income from the imparting of know-how and its ancillary services is presented in FIGURE 2.

\section{CONCLUSION}

The classification of cloud computing is fundamental to the application of the correct taxation source test. Yet, due to the inherent sophisticated nature of cloud computing activities, expressly from a taxation stance, this task seemingly becomes ambiguous as elucidated by the study of the true nature of cloud activities under the three main resources owned by CSPs. From this study it is evident that formulating guidelines that can be uniformly applied to all possible cloud computing activities is both impracticable and futile. Rather, this study attempted to formulate a broad 
spectrum of guidelines that may be used when they bear relevance to a specific cloud computing agreement. Furthermore, it is not suggested that these factors are exhaustive.

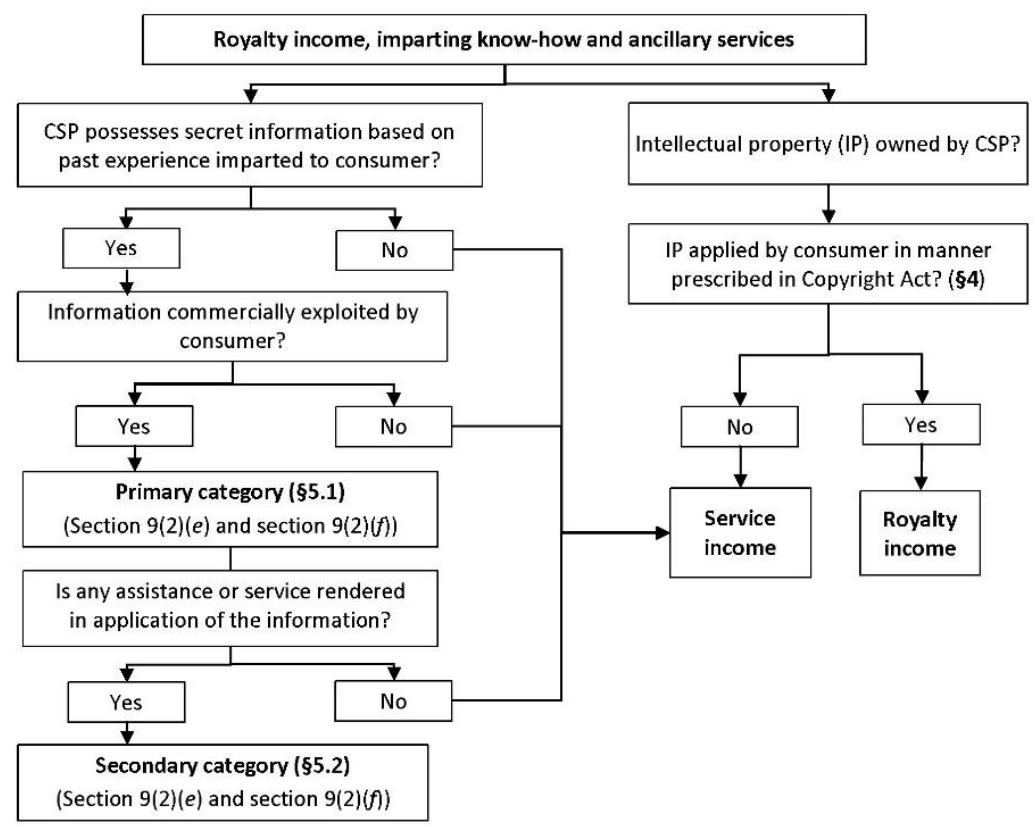

\section{FIGURE 2: Summary of guidelines: income tax classification as royalty income or from the imparting of know-how and its ancillary services}

Source: Authors'summary of the classification of intangible computing resources

It is emphasised that the underlying contract specific to each cloud computing transaction will have to be investigated scrupulously to consider all the relevant facts before the income classification is attempted. This may prove to be a time-consuming process that depends on subjective interpretations. The presence of specific guidelines on the income classification of cloud computing may therefore alleviate any challenges in this regard.

However, at the root of classifying cloud computing income it has to be considered whether the contract provides for any rights in the underlying computer resources vested in the consumer. Under this consideration it is submitted that cloud computing income may be classified as one or a combination of the following income categories:

- Lease income from tangible resources; and/or

- Royalty income; and/or

- Income from the imparting of know-how and rendering its ancillary services; and/or

- Service income, which will be classified as such by means of elimination of the above three income categories.

The aim of this study was to formulate guidelines to assist in the correct classification of cloud computing income. Such guidance is summarised under $\S 3.3$ and $\S 6$ for the use of tangible and 
intangible computer resources respectively. A concluding summary of these guidelines is also provided in TABLE 1 .

\section{TABLE 1: Concluding summary}

$\begin{gathered}\text { Guidelines formulated to consider for each category } \\ \text { of classification }\end{gathered}$
Challenges related to the application of such
guidelines

Lease income: is right to use tangible computer hardware conveyed? ( $\S 3)$

- Consumer should have bare detention of the computer hardware by means of both the prerequisites of Control (§3.1) and Intent (§3.2)

- The factors that are indicative of control have been identified as follows:

- Physical possession of; or access to the resource ( $§ 3.1 .1)$

- Decision power relating to the destination of the resource ( $\S 3.1 .2)$

- Operation of the resource ( $\S 3.1 .3)$

- Deployment model (§3.1.4)

- The bearer of risk in case of nonperformance ( $\S 3.1 .5)$

- Intent refers to the true object of the contracting parties entering a cloud agreement, which will have to be established based on the facts relevant to each specific case.

\section{Royalty income: is right to use IP conveyed? ( $\$ 4)$}

- Consumer should apply the IP of the CSP in a manner prescribed in sections $11 B$ and section $19 B(2)$ of the Copyright Act.

- Applying these guidelines is reasonably clearcut with no significant related challenges identified.

\section{Know-how income: know-how imparted or ancillary services provided? (§5.1-§5.2)}

\section{Primary category $(\S 5.1)$ :}

- The CSP should firstly possess secret information based on past experience (know-how) being of a scientific, technical, industrial or commercial nature.

- Secondly, such information should be commercially exploited by the consumer Secondary category (§5.2):

- Only once the guidelines to the primary category positive indicate that know-how has been imparted to the consumer can any service in connection to the application of such know-how fall within the scope of this category.
- It is unclear what is included within the scope of scientific, technical, industrial or commercial information referred to in section 9(2)(e) and (f) of the Act. Since cloud computing is a technology, it has been assumed that cloud activities may be of a technical nature. However, clarity in this regard is required.

- Uncertainty regarding the level of flexibility implied by the words 'in connection with' in section $9(2)(e)$ and ( $f$ ) exists. It has to be considered whether the service or assistance has to be merely related or essential to the application of know-how.

Source: Authors' analysis and summary 
In conclusion, the challenges summarised in TABLE 1 may justify further guidance from the legislature. These challenges could also possibly serve as point of focus for further research. Guidance in identifying the correct income classification is considered essential as a starting point to subsequently determine the income tax source of cloud computing activities and therefore to ensure that the South African tax base is not weakened due to uncertainties in this regard.

\section{LIST OF REFERENCES}

Concise 0xford Dictionary. (2012). 0xford University Press - 0xford Dictionaries Online. Available: http://oxforddictionaries.com. (Accessed 4 June 2013).

Commissioner of Customs and Excise v Randles Bros \& Hudson Ltd 1941 AD 369.

Cummings, R.B. (2012). Tax trends. Journal of State Taxation, 30(2), pp.7-12, 56.

Enslin, Z. (2012). Introduction to cloud computing and control objectives for information and related technologies (COBIT) - mapped benefits of cloud computing adoption. African Journal of Business Management, 6(41), pp:10568-10577.

Hellerstein, W. \& Sedon, J. (2012). State taxation of cloud computing: a framework for analysis. Journal of Taxation, 117(1), pp.11-31.

Hestermann, C. (2012). How to select the right cloud ERP. (Gartner research note, 29 November 2012.) Available:

http://my.gartner.com/portal/server.pt?open=512\&objID=260\&mode=2\&PagelD=3460702\&res/d=225 6115\&ref=QuickSearch\&sthkw=how+to+select+the+right+cloud+erp. (Accessed 19 December 2013).

Hutchinson, T. \& Duncan, N. (2012). Defining and describing what we do: Doctrinal legal research. Deakin Law Review, 17(1): 83-119.

$I A S B$, vide International Accounting Standards Board.

International Accounting Standards Board. (2010). Leases, IAS 17. London: IASB.

Leong, L. (2011). Cloud laaS: How Computer Resources Are Delivered. (Gartner research report, 3 March 2011). Available:

http://my.gartner.com/portal/server.pt?open=512\&objID=260\&mode=2\&PagelD=3460702\&res/d=157 $1717 \&$ ref=PuickSearch\&sthkw=Cloud+laaS\%3A+How+compute+resources+are+delivered. (Accessed 19 December 2013).

Mell, P. \& Grance, T. (2011). The NIST definition of cloud computing. National Institute of Standards and Technology, Maryland, USA. (Special Publication 800-145).

$0 \varepsilon C D$, vide Organisation for $\varepsilon$ conomic Co-operation and Development.

Organisation for Economic Co-operation and Development. (2003). 2002 Reports Related to the OECD Model Tax Convention. (Issues in International Taxation, No. 8, 0ECD Publishing. D0I:

10.1787/9789264099920-en)

Organisation for Economic Co-operation and Development. (2012a). Article12. Royalties. (Model Tax Convention on Income and on Capitol 2010: Full Version, OECD Publishing). Available:

http://dx.doi.org/10.1787/97892641175181-15-en. (Accessed 19 December 2013). 
Organisation for Economic Co-operation and Development. (2012b). Commentary on Article 12: Concerning the taxation of royalties. (Model Tax Convention on Income and on Capitol 2010: Full Version, 0ECD Publishing). Available: http://dx.doi.org/10.1787/9789264175181-46-en. (Accessed: 19 December 2013).

Organisation for Economic Co-operation and Development. (2012c). $R$ (2). The taxation of income derived from the leasing of industrial, commercial or scientific equipment. (Model Tax Convention on Income and on Capital 2010: Full Version, 0ECD Publishing). Available: http://dx.doi.org/10.1787/9789264175181-95-en. (Accessed: 19 December 2013).

Ogutto, A.W. (2005). Electronic commerce: challenging the income tax base. South African Mercantile Law Journal, 17(3), pp.305-322.

Smith, D.M. \& Clearley, D.W. (2012). Agenda for cloud computing, 2012. (Gartner research note, 22 February 2012). Available:

http://www.gartner.com/document/1931114? ?ref=QuickSearch\&sthkw=Agenda\%20for\%20cloud\%20c omputing\&refval=146495494\&qid=77879921681 cfbff93leal9617ada79e. (Accessed 19 December 2013).

South Africa. (1978). Copyright Act, No. 98 of 1978 (as amended). Pretoria: Government Printer.

South Africa. (1962). Income Tax Act, No. 58 of 1692 (as amended). Pretoria: Government Printer.

SARS, vide South African Revenue Service.

South African Revenue Service. (2009). Interpretation note no. 50. Available: http://sars.gov.za (Accessed 21 January 2015).

South African Revenue Service. (2012). Explanatory memorandum on the taxation laws amendment bill, 2011. Available: http://www.sars.gov.za (Accessed 10 December 2013).

USA, vide United States of America.

United States of America. Internal Revenue Code (IRC). Enacted by Congress in Title 26 of the United States Code (26 U.S.C.). Available: http://www.law.cornell.edu/uscode/text/26/7701 (Accessed 19 December 2013).

United States of America. Internal Revenue Service. (2011). Revenue Rule 2011-24. Available: http://www.irs.gov/pub/irs-drop/rr-11-24.pdf. (Accessed 19 December 2013).

United States of America. Wisconsin Department of Revenue. (2010). Private Letter Rulings W1025002 (24 March 2010).

United States of America. Wisconsin Department of Revenue. (2009). Private Letter Rulings W0921002 (3June 2009).

Van der Walt, A.J. \& Pienaar, G.J. (1999). Inleiding tot die Sakereg, $3^{\text {de }}$ uitgawe. [Introduction to Law of Things, $3^{\text {rd }}$ ed.]. South Africa: Juta and Co. Ltd.

Wesson, N. (1999). Die invloed van internet op die toepaslikheid van die bronreëls in terme van die Inkomstebelastingwet, no. 58 van 1962 [The effect of the internet on the applicability of the source rules included in the Income Tax Act no 58 of 1963]. Unpublished MAcc thesis. Stellenbosch: Stellenbosch University.

Zandberg v Van Zy/1910 AD 302. 